\title{
La saliva y su papel en la trasmisión del covid-19 - lo que el odontólogo necesita saber
}

\author{
Saliva and its role in the transmission of covid-19 - what the dentist needs to know
}

\author{
Marco Rocafuerte ${ }^{1 a}$
}

\section{RESUMEN}

La enfermedad por coronavirus 2019 (COVID-19) es una infección causada por un nuevo tipo de coronavirus recientemente descubierto. El virus COVID-19 se propaga principalmente a través de gotas de saliva o secreción de la nariz cuando una persona infectada tose o estornuda y esto es una alerta para todos los odontólogos. Por tal motivo, se realizó una búsqueda manual de la literatura relevante con los objetivos de determinar el riesgo que tiene la saliva de un paciente infectado con COVID-19 (sintomático o asintomático), así como, su mecanismo de trasmisión y el potencial de contagio al que se encuentran expuestos los profesionales de la salud bucal

PALABRAS CLAVE: Saliva; Covid 19; Aerosol .

\section{ABSTRACT}

The COVID-19 is an infectious disease caused by a new type of coronavirus which has been recently discovered. This virus is spread mainly through droplets of saliva or discharged from the nose when an infected person coughs or sneezes and this is an alert for all the dentists. For that reason, a relevant research has been done on this matter in order to determine the risk of the saliva of a patient infected with COVID-19 (symptomatic or asymptomatic), as well as its mechanism of transmission and the potential for contagion to which oral health professionals are exposed.

KEY WORDS: Saliva; Covid 19; Aerosol

${ }^{2}$ Universidad Complutense de Madrid. España.

${ }^{a}$ Docente

${ }^{\mathrm{b}}$ Especialista en Medicina Oral

Correspondencia:

Marco Rocafuerte

Correo electrónico: mrocafuerte@gmail.com
Este es un artículo Open Access distribuido bajo la licencia Creative Commons Atribución-No ComercialCompartir Igual 4.0 


\section{INTRODUCCIÓN}

Un nuevo brote de enfermedad por coronavirus ha surgido y está extendiéndose rápidamente por todo el mundo. Los coronavirus (CoV) son una amplia familia de virus que pueden causar diversas afecciones, desde el resfriado común, hasta infecciones respiratorias graves. El agente causal es el virus SARS-COV-2 (síndrome respiratorio agudo severo por sus siglas en inglés) y la enfermedad que causa fue denominada por la Organización Mundial de la Salud (OMS) como COVID-19 ${ }^{(1)}$.

Se ha informado que el biofluido generado en gran medida por la saliva a partir de las glándulas salivales en la cavidad oral es positivo para el ácido nucleico del COVID-19. Además de los pulmones, las glándulas salivales y la lengua son posiblemente otros anfitriones debido a la expresión de la enzima convertidora de angiotensina (ECA-2) ${ }^{(2)}$.

La transmisión por gotitas de saliva (flügge) es un modo primario para que el SARS-COV-2 se difunda según lo afirma la OMS. EI COVID-19 está asociado con la transmisión por contacto directo o cercano de persona a persona y ha sido detectado recientemente en la saliva de pacientes infectados por lo que esta puede tener un papel importante en la transmisión del SARS-COV-2 ${ }^{(3)}$

El odontólogo debe estar familiarizado con el COVID19 o, al menos, con los mecanismos de prevención del contagio directo, así como de las posibles infecciones cruzadas o del papel como vector importante en las vías de transmisión del virus, igual que lo estamos con otro tipo de infecciones por lo tanto, los objetivos del presente artículo son: determinar el riesgo que tiene la saliva de un paciente infectado con COVID-19 (sintomático o asintomático), así como, su mecanismo de trasmisión y el potencial de contagio al que se encuentran expuestos los profesionales de la salud bucal.

\section{METODOLOGÍA}

La revisión se basó fundamentalmente en la búsqueda de información en revistas indexadas a PubMed, NBCl y Scielo, con la utilización de descriptores como "saliva y COVID-19", "COVID19 y vías de trasmisión", "saliva y aerosoles". Fueron tenidos en cuenta los siguientes criterios. Criterios de inclusión: Idiomas español, inglés; cualquier área geográfica o país; publicado desde el 1990 hasta el 2020. El análisis se centró en la exposición y síntesis de los resultados de los artículos revisados.

\section{SALIVA}

El término saliva hace referencia a un fluido oral que surge de la combinación de líquidos que hay en la cavidad bucal. El conjunto de estos líquidos está compuesto, además de las secreciones de las glándulas salivales, por una mezcla de pequeñas partículas alimentarias, microorganismos, células de descamación del epitelio oral, secreción del fluido gingival, secreción de las glándulas sebáceas entre otras partículas $^{(4)}$.

La saliva se produce tanto por las glándulas mayores (parótidas y submandibulares y sublinguales) como las menores, con diferentes componentes y propiedades entre los dos grupos. Es un líquido acuoso incoloro, inodoro e insípido que contiene $99 \%$ de agua y $1 \%$ de sustancias orgánicas e inorgánicas y gases disueltos, principalmente oxígeno y dióxido de carbono. Los componentes salivales se pueden agrupar en proteínas (amilasa y lisozima), moléculas orgánicas (urea, lípidos y glucosa principalmente) y electrolitos (sodio, calcio, cloro y fosfatos) ${ }^{(5)}$.

La secreción diaria oscila entre 500 y $700 \mathrm{ml}$, con un volumen medio en la boca de $1,1 \mathrm{ml}$. En reposo, la secreción oscila entre 0,25 y 0,35 $\mathrm{ml} / \mathrm{mn}$ y procede sobre todo de las glándulas submandibulares y sublinguales. Ante estímulos sensitivos, eléctricos o mecánicos, el volumen puede llegar hasta $1,5 \mathrm{ml} / \mathrm{mn}$. El mayor volumen salival se produce antes, durante y después de las comidas, alcanza su pico máximo alrededor de las 12 del mediodía y disminuye de forma muy considerable por la noche, durante el sueño ${ }^{(6)}$.

La saliva desempeña un papel central en el mantenimiento de la salud bucal, regulando $y$ manteniendo la integridad de los tejidos orales duros y blandos. Lubrica y limpia la cavidad bucal, posee propiedades antibacterianas, antivirales y antifúngicas, amortigua el $\mathrm{pH}$, ayuda a masticar, hablar, la deglución y la digestión, promueve el sabor y contribuyen al mantenimiento y la remineralización de los dientes ${ }^{(7)}$. Además, la saliva tiene un alto potencial como muestra para evaluar el estado de salud de las personas por tal motivo viene siendo utilizada como herramienta en el diagnóstico de diversas enfermedades (enfermedades orales, cáncer, diabetes, estrés y otras afecciones sistémicas) ${ }^{(8)}$

Por otra parte, la cavidad bucal es una vía de entrada y salida del cuerpo humano, y se supone que la saliva desempeña un papel en el diagnóstico precoz y la transmisión por contacto cercano de enfermedades infecciosas. Sobre todo la sangre y saliva del paciente se propagan como 
aerosoles y gotas durante los tratamientos dentales y se consideran fuentes potenciales de contaminación cruzada, aumentado la probabilidad de posibles infecciones microbianas no solo en pacientes sino también en el personal odontológico $^{(9)}$. Los aerosoles y las salpicaduras contaminantes también pueden extenderse a las superficies de herramientas y equipos así como a todos los ambientes y entorno del consultorio ${ }^{(10)}$.

\section{COVID-19}

Un brote de neumonía emergente se originó en la ciudad de Wuhan (República popular de China) a finales de diciembre de 2019. La infección por neumonía se desarrolló rápidamente y se extendió desde Wuhan a la mayoría de las otras provincias y otros 24 países. La OMS declaró un estado de salud pública de emergencia y preocupación internacional por este brote neumonía atípica el 30 de enero de $2020^{(11)}$

Actualmente, al 15 de mayo del 2020, el nuevo coronavirus ya ha infectado a más de 4,4 millones de personas en todo el mundo y provocado la muerte de casi 303,000 personas. Se estima que entre el $50 \%$ y el $80 \%$ de la población mundial puede infectarse con el nuevo SARS-CoV-2. El tiempo promedio entre los primeros síntomas y la muerte de un paciente es de 17 días, mientras que los pacientes que se recuperan tardan una media de 22 días en recibir el alta ${ }^{(12,13)}$.

El agente infeccioso de esta neumonía viral atípica que se presentó en Wuhan finalmente se identificó como un nuevo coronavirus (2019-nCoV), el séptimo miembro de la familia de coronavirus que infecta a los humanos. El 11 de febrero de 2020, la Organización mundial de la salud (OMS) nombró a la nueva neumonía viral como "Enfermedad del coronavirus (COVID19)", mientras que el Comité internacional de taxonomía de virus (ICTV por sus siglas en inglés) sugirió este nuevo nombre de coronavirus como "SARS-CoV-2" debido a la filogenética y Análisis taxonómico ${ }^{(14)}$.

El nuevo coronavirus SARS-CoV2, fue identificado como el agente etiológico de la enfermedad por coronavirus 2019 (COVID-19) ${ }^{(15)}$. Este virus fue incluido dentro de la categoría taxonómica de los Coronaviridae, CoV, o Coronavirus, llamado así por las extensiones que lleva encima de su núcleo que se asemejan a la corona solar. Actualmente existen 4 géneros de coronavirus: $\alpha-\mathrm{CoV}, \mathrm{B}-\mathrm{CoV}$, $\mathrm{Y}$-CoV y $\delta$-CoV. El 2019-n CoV encontrado en Wuhan también pertenece al B-CoV de acuerdo a su análisis filogenético basado en sus cromosomas virales (16). El genoma del virus SARS-CoV-2 codifica cuatro proteínas estructurales: la proteína S (spike protein), la proteína $E$ (envelope),la proteína M (membrane) y la proteína $\mathrm{N}$ (nucleocapsid) ${ }^{(17)}$.

El coronavirus son virus de ARN trenzados, y dos cepas de ellos, el coronavirus del síndrome respiratorio agudo severo (SARS-CoV) y el coronavirus del síndrome respiratorio del Medio Oriente (MERS-CoV), son de origen zoonótico y se sabe que causan enfermedades respiratorias fatales como el 2019-nCoV. Debido a la amplia distribución y la recombinación genómica de los coronavirus, el 2019-nCoV es el nuevo coronavirus y se ha demostrado que tiene una mayor tasa de infección ${ }^{(18)}$.

Los signos y síntomas del 2019-nCoV presentes en los pacientes al inicio de la enfermedad varían, pero a lo largo del curso de la misma, la mayoría de las personas experimentarán lo siguiente ${ }^{(19,20)}$.

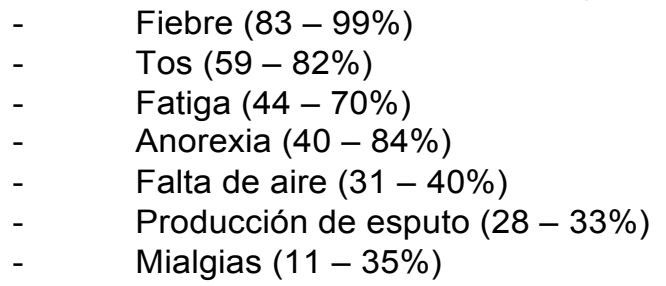

Actualmente se han encontrado cuadros de anosmia y ageusia en el curso de la COVID-19 y otras infecciones por coronavirus pero representa una ocurrencia rara $(5.1 \%$ y $5.6 \%$ respectivamente) ${ }^{(21)}$.

En general, la edad avanzada y la existencia de comorbilidades subyacentes (diabetes, hipertensión, fumadores crónicos, enfermedad cardiovascular, entre otras) se han asociado con un peor pronóstico ${ }^{(22)}$.

La vía de transmisión entre humanos se considera similar al descrito para otros coronavirus a través de las secreciones de personas infectadas, principalmente por contacto directo con gotas respiratorias de más de 5 micras (capaces de transmitirse a distancias de hasta 2 metros) y las manos o los fómites contaminados con estas secreciones seguido del contacto con la mucosa de la boca, nariz u ojos. El SARS-CoV-2 se ha detectado en secreciones nasofaríngeas, incluyendo la saliva ${ }^{(23)}$.

Aun así, se ha reportado un caso por infección de COVID-19 en Alemania, que indica que la transmisión del virus también puede ocurrir a través del contacto con pacientes asintomáticos (24)

Desafortunadamente, debido a la alta infectividad y al flujo de viajes desde Wuhan a otras ciudades de China, Asia y el mundo, fue imposible contener el virus, de modo que, muchos casos aún 
asintomáticos comenzaron a propagarse. La COVID-19 llegó a América Latina y el Caribe el día 25 de febrero de 2020, cuando el Ministro de Salud de Brasil confirmó el primer caso, desde entonces, se ha presentado una propagación masiva en la región, superando en la actualidad los 383,000 casos de pacientes contagiados de COVID-19 ${ }^{(25)}$. El 6 de Marzo del 2020, se confirmó el primer caso de coronavirus en el Perú. Al día de hoy (15 de mayo del 2020), nuestro país ocupa el segundo lugar en Sudamérica que presenta el mayor número de casos acercándose a los 85,000 infectados ${ }^{(26)}$

\section{SALIVA Y SU POTENCIAL RIESGO EN LA TRASMISION DEL COVID-19}

La mayoría de las infecciones virales ocurren a través de las membranas mucosas. La boca y los ojos son sitios comunes para la entrada de los virus, aunque las infecciones virales tanto del ojo como de la cavidad oral son relativamente raras. El mecanismo para el control de la infección viral incluye muchas biomoléculas, incluidas mucinas, anticuerpos y proteínas antivirales que están presentes en un flujo salival y lacrimal continuo y líquido ${ }^{(27)}$.

Los aerosoles producidos por la saliva se clasifican según el tamaño de sus partículas en: partículas gruesas son de 2.5 a 10 micras, las partículas finas son de menos de 2.5 micras y las partículas ultra finas son de menos de 0.1 micras. Los aerosoles producidos por las personas cuando respiran, hablan y tosen generalmente tienen entre 0.7 micras y alrededor de 10 micras completamente invisibles a simple vista y pueden flotar fácilmente en el aire. Estos aerosoles son principalmente fluidos biológicos de la boca y los pulmones de las personas y pueden contener fragmentos de material genético del virus. La nariz

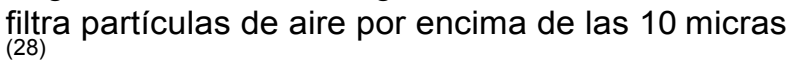

Si su tamaño es menor, puede ingresar al sistema respiratorio. Si es inferior a 2,5 micras, puede ingresar a los alvéolos. Una partícula de menos de 0.1 micras, o una partícula ultra fina como el virus COVID-19, puede ingresar al torrente sanguíneo y a órganos diana como el corazón y el cerebro. El consenso científico actual es que la mayor parte de la transmisión a través de las secreciones respiratorias ocurre en forma de gotas respiratorias grandes en lugar de pequeños aerosoles. Las gotas suelen ser lo suficientemente pesadas como para no viajar muy lejos; en cambio, caen del aire después de viajar hasta seis pies $(1.82 \mathrm{~m})^{(29)}$. Figura 1.
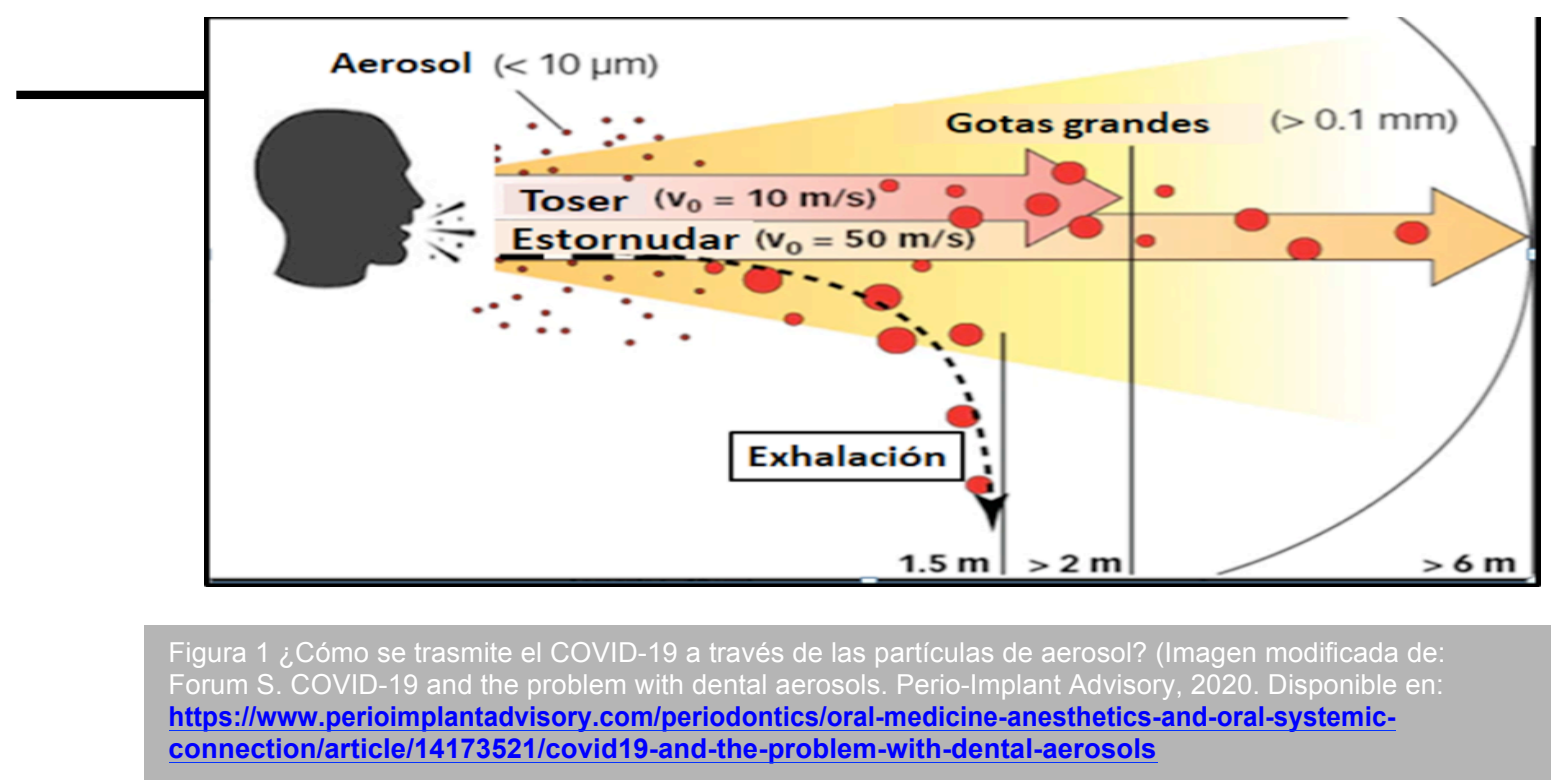

Estas partículas de aerosol son muy fáciles de inhalar al momento de hablar, toser o al realizar algún tipo de tratamiento dental lo que sugiere un problema debido a que pueden viajar a través de distancias mayores, con estimaciones de hasta 20 pies, de una persona infectada y luego provocar infecciones secundarias en el medio ambiente. El virus es viable en aerosoles suspendidos hasta tres horas. Esto quiere decir, que las gotas de aerosol pueden permanecer en un área, 
suspendidas en el aire, incluso después de que la persona que las emitió se haya ido y, por lo tanto, puede infectar a los trabajadores de la salud y contaminar diversos fomites ${ }^{(30)}$

Estos son algunos ejemplos de la longevidad de COVID-19 en algunos lugares:

- El virus es viable hasta 72 horas en superficies de plástico y acero inoxidable.

- El virus es viable hasta 24 horas en superficies de cartón.

- El virus es viable 9 horas en superficies de cobre (31)

\section{VULNERABILIDAD DEL ODONTOLOGO FRENTE AL COVID-19}

El New York Times le recordó al mundo que la odontología tenía el mayor riesgo de cualquier profesión en relación con COVID-19. Sin embargo, ¿Qué tan aceptable es el riesgo que corren los odontólogos durante la pandemia del COVID-19?. Inicialmente, el Servicio de Salud Nacional del Reino Unido nos informó que la atención odontológica general debería continuar a menos que los pacientes tuvieran síntomas o antecedentes de contacto cercano y que tanto odontólogos como pacientes usemos el equipo de protección personal y las normas de bioseguridad adecuados. EI SARS-CoV-2, es muy pequeño, de aproximadamente 0.1 micras, aproximadamente 4 millonésimas de pulgada de diámetro ${ }^{(32)}$.

Algunos autores como Sabino-Silva, mencionan que existen al menos tres vías por la cual la COVID-19 puede estar presente en la saliva del paciente infectado: presencia del SARS-CoV-2 en las vías aéreas superiores, en la sangre, el cual puede acceder a la cavidad bucal a través del fluido crevicular y por la infección de una glándula salival a través de la liberación de partículas en la saliva por medio de los conductos salivales, ya que se ha demostrado que el SARS-CoV-2 pudo infectar células epiteliales de glándulas salivales en animales ${ }^{(33)}$.

Los investigadores aún no saben cuánta cantidad de SARS-CoV-2 puede contener un aerosol producido por la tos de una persona infectada. Pero en un estudio piloto, se utilizó un modelo para estimar que una persona de pie y hablando en una habitación podría liberar hasta 114 dosis infecciosas por hora. Los investigadores predicen que estos fragmentos de saliva en aerosol infectarían fácilmente a otras personas si esto sucediera en espacios públicos cerrados ${ }^{(34)}$.

Se postula que el SARS-CoV-2 se transmite principalmente a través de la dispersión de gotas, pero se sabe poco sobre la carga de SARS CoV-2 en los aerosoles orales. Para ello Kung Wang y Cols. examinaron muestras de la garganta y la saliva y encontraron grandes cantidades de ARN

del SARS-CoV-2. De ambas muestras se encontró mayor cantidad de SARS-CoV-2 en la saliva ${ }^{(35)}$.

Estudios científicos actuales, han demostrado que la lengua así como el conducto de las glándulas salivales mayores contienen elevadas cantidades de receptores ECA-2 que van a facilitar la entrada del coronavirus a la célula y junto con los pulmones e intestino delgado son zonas predilectas para la fijación de las proteínas spike del coronavirus.

Con el fin de investigar las posibles rutas de la infección en la SARS-COV-2 mucosa de la cavidad oral, $X u$ y Cols demostraron que el ECA-2 podía expresarse en la cavidad oral y estaba altamente enriquecido en células epiteliales. Además, entre los diferentes sitios orales, la expresión de ECA-2 fue mayor en la lengua que en los tejidos bucales y gingivales. Estos hallazgos indicaron que la mucosa de la cavidad oral puede ser una ruta de riesgo potencialmente alto de infección por 2019-nCov ${ }^{(36)}$.

En los últimos días, se hace referencia del término carga viral en pacientes infectados. Este concepto se usa para cuantificar el grado de infección del virus, a partir de la estimación de la cantidad de partículas víricas en los fluidos corporales, por ejemplo, en la sangre o saliva. Por ahora, sabemos que la carga viral del coronavirus se relaciona con la gravedad de la COVID-19. Una investigación dirigida por el profesor $\mathrm{Fu}-$ Woo, demostró niveles de carga viral hasta 60 veces más altos en pacientes con síntomas más graves en comparación con aquellas personas infectadas sin síntomas $\left.{ }^{(37}\right)$.

Existe una preocupación creciente por la disminución de la calidad del aire y la posible contaminación por aerosoles en el consultorio dental. Este problema ha sido abordado por los Centros para el Control y la Prevención de Enfermedades, que recomiendan que se minimicen todas las fuentes de salpicaduras $y$ aerosoles contaminados con sangre ${ }^{(38)}$.

Sin embargo, los tratamientos odontológicos a menudo implican procedimientos quirúrgicos en los que se usan generalmente jeringas de aire o agua, turbinas de alta velocidad, micromotores y raspadores ultrasónicos. Estos dispositivos producen aerosoles que contienen agentes potencialmente infecciosos, como aquellos encontrados en la sangre, la saliva y la cavidad 
oral del paciente ${ }^{(39)}$.

Los odontólogos que realizan tratamientos utilizando aerosolización (convertir ciertas

sustancias físicas en la forma de partículas pequeñas y suficientemente ligeras para ser transportadas en el aire) corren un riesgo extremadamente elevado de inocularse a sí mismos, a sus asistentes dentales, a otros miembros del personal de su centro de labores y a la reinoculación de los pacientes ${ }^{(40)}$.

El mayor peligro de trasmisión por las salpicaduras y gotas a la cara media del odontólogo y su asistente, así como, al área nasal del paciente ${ }^{(41)}$. Además el tratamiento periodontal tiene una incidencia mucho mayor de trasmisión de gotas que otros tipos de tratamientos odontológicos ${ }^{(42)}$.

Harrel y Molinari demostraron que la trasmisión ultrasónica y sónica durante los procedimientos no quirúrgicos tuvo una mayor incidencia de trasmisión de partículas, seguido por el pulido por aire, jeringa triple y aerolización de piezas de mano de alta velocidad ${ }^{(43)}$.

Shpuntoff, demostró que estos aerosoles precipitan por la gravedad quedando en las superficies, y las microgotas quedan suspendidas en el aire por varias horas, constituyendo un riesgo, ya que pueden ser inhaladas ${ }^{(44)}$.

Del mismo modo, algunos estudios como el realizado por Bustamante y Herrera, han demostrado que el aerosol generado por el uso de la turbina dentro de la cavidad bucal, emite cerca de 1.000 unidades formadoras de colonias bacterianas, otros han reportado que los microorganismos se han encontrado a 1,80 m. de la turbina en uso. Las concentraciones más altas de microorganismos se encontraron a $60 \mathrm{~cm}$ enfrente al paciente. Se ha reportado que las bacterias generadas por el uso del limpiador ultrasónico (scaler) pueden permanecer en el aire por 24 horas $^{(45)}$.

Otro estudio encontró que la instrumentación ultrasónica puede transmitir 100,000 microbios por pie cúbico con una aerosolización de hasta seis pies, y, si hay corriente de aire inadecuada, los microbios pueden durar de 35 minutos a 17 horas (46)

Así mismo los Cirujanos Orales y Maxilofaciales son particularmente vulnerables a la infección por COVID-19 debido a que trabajan muy cerca de la cavidad oral y nasal y se encuentra en contacto con fluidos orgánicos en su práctica de rutina, por lo que, se deben realizar procedimientos de urgencia. Se recomiendo que los procedimientos de emergencia sean derivados a un hospital debido al riesgo elevado de aspiración de

aerosoles y la distancia de trabajo, habitualmente, es inferior a un metro y esto podría provocar un contagio directo al odontólogo. Con el fin de proporcionar recursos sanitarios adecuados para el tratamiento de pacientes con COVID-19 gravemente enfermos, tiene sentido no realizar procedimientos electivos durante un intervalo de tiempo bien definido que debe reevaluarse regularmente ${ }^{(47)}$.

Por lo tanto, después de este esfuerzo mundial por promover el distanciamiento social, la práctica de estrategias para bloquear y prevenir la transmisión del virus SARS-CoV-2 durante el diagnóstico y tratamiento odontológico deben incluir una evaluación completa del paciente, una higiene de manos rigurosa, el uso de equipos de protección personal (mascarilla, gorro, mandilón, gafas, etc.) tanto para el odontólogo así como todo su personal de apoyo, enjuagues bucales antes de cualquier procedimiento dental, el uso de piezas de mano anti-retracción, aislamiento con dique de goma, uso de eyectores de saliva, el uso de un protector facial para proteger las mucosas de los ojos, nariz y boca durante los procedimientos dentales, así como, la desinfección de todas las áreas y manejo de residuos médicos del consultorio ${ }^{(10,11)}$.

\section{CONCLUSION}

La cavidad bucal es el lugar de mayor riesgo donde se produce la trasmisión del COVID-19. Teniendo en cuenta que COVID-19 se ha identificado recientemente en la saliva de pacientes infectados, nosotros como parte de los profesionales de la salud bucal siempre debemos ser miembros activos en la prevención de la propagación de enfermedades infecciosas. A la vez esto nos brinda la oportunidad de determinar un diagnóstico no invasivo a través de la saliva para COVID-19 que puede ayudar a detectar dicho virus y de esta manera reducir su propagación. No debe subestimarse el riesgo de que un odontólogo sea positivo para COVID-19 e infecte potencialmente a pacientes que asisten a servicios odontológicos de emergencia. Deben establecerse medidas proactivas y preventivas como protocolo principal para contener la propagación del virus.

Contribuciones de autoría: MR Participó en la revisión de la información, redacción y aprobación del artículo.

Fuente de financiamiento: Autofinanciado. 
Conflictos de interés: No se declaró conflictos de interés.

\section{REFERENCIAS}

1. Aquino Canchari CR. Coronavirus COVID-19 y su repercusión en la Odontología. Rev Cubana Estomatol 2020;57(1):1-5. Disponible en: http://www.revestomatologia.sld.cu/index. $\mathrm{php} / \mathrm{est} / \mathrm{articl}$ e/view/3242

2. Xu R., Cui B., Duan., Zhang P., Zhou X. Saliva: potential diagnostic value and transmission of 2019- nCoV. International Journal of Oral Science 2020; 12(11). DOI: https://doi.org/10.1038/s41368-020-0080- z

3. Sri Santosh T. A Review of Salivary Diagnostics and Its Potential Implication in Detection of Covid19. Cureus 2020; 12(4):110.

4. Sociedad Española de Epidemiología y Salud Pública Oral (SESPO). Simposio sobre: Saliva y Salud Dental. Valencia. PromoLibro; 1998.

5. Lorgulesco G. Saliva between normal and pathological. Important factors in determining systemic and oral health. J Med Life. 2009; 2(3): 303-07.

6. Llena P. The role of saliva in maintaining oral health and as an aid to diagnosis. Med. oral patol. oral cir.bucal 2006; 11(5): 449-55.

7. Acevedo A. Saliva and oral health. Rev. Assoc. Med. Bras. 2010; 56(1): 1-9.

8. Zi Zhang Ch., Qun Cheng Z. Saliva in the diagnosis of diseases. International Journal of Oral Science 2016; 8: 133-13.

9. Xian X., Xu X., Cheng L. Transmission routes of 2019- nCoV and controls in dental practice. International Journal of Oral Science 2020; 12(9): 1-6.

10. Watanabe A., Tamaki N., Yokota K., Use of ATP bioluminescence to survey the spread of aerosol and splatter during dental treatments. J Hosp Infect. 2018 Jul; 99(3):303-5.

11. Jun S., Jinjun J., Ling Y. 2019 novel coronavirus of pneumonia in Wuhan, China: emerging attack and management strategies. Clin Transl Med. 2020; 9: 19

12 . Verity R. et al. Estimates of the severity of coronavirus disease 2019: a model-based analysis. Lancet Infect Dis 2020.

DOI: 3099(20)30243-7. https://doi.org/10.1016/S1473-

13. COVID 19 Dashboard by the Center for Systems Science and Engineering (CSSE) at Jhons Hopkins University (JHU) [Internet] 2020 [cited 2020 Mar 24\} https://coronavirus.jhu.edu/map.html

14. Ather et al. Coronavirus Disease 19 (COVID19): Implications for Clinical Dental Care. JOE 2020; 45(5): 1-11.
15. Sigua E, Bernal J., Lanata A. y Cols. Covid y la Odontología: una Revisión de las recomendaciones y perspectivas para Latinoamérica. Int. J. Odontostomat 2020; 14(3): 299-309.

16. Heng L., Shang-Ming L., Xiao-Hua Y. Coronavirus disease 2019 (COVID-19): current status and future perspectives. Int $\mathrm{J}$ Antimicrob Agents. 2020.

17. Mousavizadeha L., Ghasemi S. Genotype and phenotype of COVID-19: Their roles in pathogenesis. J Microbiol Immunol Infect. 2020. Disponible en: https://www.ncbi.nlm.nih.gov/pmc/articles/PMC 7139247/pdf/main.pdf

18. Zi-Wei Y., Shuofeng Y., Kit-San Y. Zoonotic origins of human coronaviruses. Int. J. Biol. Sci. 2020, 16: 1686-97.

19. Guan WJ, Ni ZY, $\mathrm{Hu}$ Y, et al. Clinical Characteristics of Coronavirus Disease 2019 in China. The New England journal of medicine. $2020 . \quad$ Disponible en https://www.nejm.org/doi/pdf/10.1056/nejmoa20 02032

20. Chen N, Zhou M, Dong $X$, et al. Epidemiological and clinical characteristics of 99 cases of 2019 novel coronavirus pneumonia in Wuhan, China: a descriptive study. Lancet (London, England). 2020; 395:507-513.

21. Vaira L., Salzano G. Anosmia and Ageusia: Common Findings in COVID-19 Patients. The Laryngoscope 2020. DOI: 10.1002/lary.28692.

22. Guan W-jie, Liang W-hua, Zhao Y, et al. Comorbidity and its impact on 1590 patients with Covid-19 in China: A Nationwide Analysis. Eur Respir J $2020 . \quad$ DOI: https://doi.org/10.1183/13993003.00547-2020.

23. https://www.mscbs.gob.es/profesionales/saludP ublica/ccayes/alertasActual/nCovChina/docume ntos/20200326_ITCoronavirus.p df

24. Rothe, C. et al. Transmission of 2019-nCoV infection from an asymptomatic con- tact in germany. N. Engl. J. Med. 2020. DOI: https://doi.org/10.1056/NEJMc2001468 (2020).

25. Sánchez J., Rodriguez A., Arce L. Enfermedad por Coronavirus 2019 (COVID-19) en América Latina: Papel de la atención primaria en la preparación y respuesta. Atención primaria 2020.

DOI: https://doi.org/doi:10.1016/j.aprim.2020.04.001

26. https://www.gob.pe/8662-ministerio-de-saludcoronavirus-en-el-peru

27. Corstjens P, Abrams W, Malamud D. Saliva and viral infections. Periodontology 2000. 2016; 70 : 93-110.

28. Zayas, G., Chiang, M.C., Wong, E. et al. Cough aerosol in healthy participants: fundamental knowledge to optimize droplet-spread infectious respiratory disease management. BMC Pulm $\begin{array}{llll}\text { Med } 12, & 11 & \text { (2012). }\end{array}$ https://doi.org/10.1186/1471-2466-12-11. 
29. Van Doremalen N, Bushmaker T, Morris $\mathrm{DH}$, et al. Aerosol and surface stability of SARS-CoV-2 as compared with SARS-CoV-1. N Engl J Med. Published online March 17, 2020. DOI:10.1056/NEJMc2004973

30. Jones R., Brosseau L. Aerosol Transmission of Infectious Disease. JOEM 2015; 57(5): 501-508.

31. Kampf G., Todt T. Persistence of coronaviruses on inanimate surfaces and their inactivation with biocidal agents. Journal of Hospital Infection 2020; 104: 246-251.

32. Coulthard P. Dentistry and coronavirus (COVID19) - moral decision-making. Br Dent J. 2020 Apr;228(7):503-505.

33. Sabino-Silva R, Jardim ACG, Siqueira WL. Coronavirus COVID-19 impacts to dentistry and potential Salivary diagnosis. Clin Oral Inv. 2020. Clinical Oral Investigations (2020) 24: 16191621.

34. https://theconversation.com/coronavirus-driftsthrough-the-air-in-microscopic-droplets-heres-thescience-of-infectious-aerosols- 136663

35. Kung Wang W., Ying Chen S., Jung Liu I. et al. Detection of SARS-associated Coronavirus in Throat Wash and Saliva in Early Diagnosis. Emerging Infectious Diseases 2004; 10(7): 12139.

36. Hao X., Liang Z., Jiaxin D., Jiakuan P. High expression of ACE2 receptor of 2019-nCoV on the epithelial cells of oral mucosa. International Journal of Oral Science 2020; 12(8).

37. Jasper Fuk-Woo C. et al. A familial cluster of pneumonia associated with the 2019 novel coronavirus indicating person-to-person transmission: a study of a family cluster. Lancet 2020; 395: 514-23.
38. Hasel S., Barnes J., Rivera F. Reduction of aerosols produced by ultrasonic scalers. J Periodontol. 1996; 67(1):28-32.

39. Meng L., Hua F., Bian Z. Coronavirus disease 2019 (COVID-19): Emerging and future challenges for Dental and Oral Medicine. Journal of Dental Research 2020, Vol. 99(5) 481-7.

40. Kobza J., PastuszkaS, BraggoszewskaE. Do exposures to aerosols pose a risk to dental professionals?. Occup Med (Lond). 2018; 68(7): 454-8.

41. Nejatidanesh F. et al. Risk of Contamination of different areas of dentist's face during dental practices. Int J Prev Med. 2013; 4(5): 611-5.

42. Sawhney A. et al. Aerosols How dangerous they are in clinical practice. J Clin Diagn Res. 2015; 9(4): 52-7.

43. Harrel SK, Molinari J. Aerosol and splatter in dentistry: a brief review of the literature and infection control implications. J Am Dent Assoc. 2004; 135(4):429-437.

44. Shpuntoff, H. \& Shpuntoff, R. L. High-speed dental handpieces and spread of airborne infections. N. Y. State Dent. J. 1993, 59(1):21-3.

45. Bustamante M., Herrera J. Contaminación Bacteriana Generada por Aerosoles en Ambiente Odontológico. Int. J. Odontostomat. 2014; 8(1): 99-105.

46. Miller RL. Characteristics of blood-containing aerosols generated by common powered dental instruments. Am Ind $\mathrm{Hyg}$ Assoc J. 1995;56(7):670-6.

47. Yang Y., Hui Yuh S., Zhi Gang C. Experience of Diagnosing and Managing Patients in Oral Maxillofacial Surgery during the Prevention and Control Period of the New Coronavirus Pneumonia. Chin J Dent Res. 2020; 23(1):57-62. 